Review Article

\title{
Keeping a Healthy Figure Scientifically
}

\author{
Zhang J* \\ School of Physical Science and technology, Lanzhou University, China
}

\begin{abstract}
In a paper published on scientific American, February 2017, proposed that physical exercising does no help to energy expenditure so is useless to losing obesity. However, this is unbelievable and rebels the fact that exercising consume energy; furthermore, those who keep exercising and are good at sports are always very healthy with good figure, and their abilities to learn are remarkably higher than those who don't exercise, such as Bruce Lee and many athletes on Olympics. It is a puzzle how the result in this paper was got. Read the paper carefully, noticing that the comparison is between the European people who think more and the Hadza people who only live on hunting and gathering, a relatively primary stage of the society, Hadza people have physical exercising while hunting but they don't think therein, they just try every place out to find the poisoned giraffe without thinking where had it gone, without any theory or certainty. The way how Hadza people live is mechanical, like the sheep who only eat, drink and reproduce the next generation who live in same way as their ancestors, they don't think to pursue what they like and to live better; therefore, it is their cutting down their thinking and learning that made their same expenditure as Europeans who don't exercising, not their physical exercising itself doesn't increase their energy expenditure. Using more nutriology, exercising exactly helps to losing obesity and it has better effect thereto as combined with learning, learning consumes the blood glucose first which is advantageous to fat burning in physical exercising. Learning and exercising make oneself be better so that he lives better thereby, physical exercising also has many other beneficial effects to human's health and cleverness etc., it is a perfect way for man to lose obesity and keep healthy to combine proper physical exercising with more thinking and learning. One should learn as well as exercise to lose obesity and keep healthy, so that one could have a healthy figure as well as be better and live better thereby.
\end{abstract}

Keywords: Obesity, Health, Exercise, Learn, Live better

\section{Does Exercise Really Have No Help to Calories Burning?}

In the paper "Exercise Paradox" written by Herman Pontzer it proposed that exercise does not help to increasing energy expenditure because the people in Hadza have energy expenditure not different from people in Europe, though European seldom exercise and Hadza men have large amount of physical exercise every day. However, this rebels the facts that exercising effectively expends energy and discourages people from physical exercising, for it assumes that it does not help controlling obesity to exercise.

In the original paper, the researchers investigated a group of Hadza people who preserve the most primate way of living: hunting and gathering, the men have better physical abilities so they promote it to hunt wild animals for eating, while the women find and gather foods from wild plants to feed their family. Measuring their energy expenditure by doubly labeled water through their drinking, the researchers found that their energy expenditure has no difference with that of European people who stay in office only have mental works. As those European seldom exercise and the Hadza people have many physical exercises when they are hunting, but they have same energy expenditure, i.e., spending same calories every day, this seems that exercising has no effect for increasing energy burning so that it does no help to weight losing. How could this be? Exercise factually costs energy because one need to move, as one moves one must burn calories for work, sport itself is a process that burns calories, all energy comes from the chemical energy stored in what man ate, why exercising more doesn't change the energy expenditure, leaving people that the energy expenditure is constrained in this research?

\begin{tabular}{|l|l|}
\hline Quick Response Code: & *Corresponding author: Jiayi Zhang, Theoretical Physics Class 3, Lanzhou, Gansu, 730070, \\
China \\
Received: 20 September, 2021 & Published: 18 October, 2021 \\
& Citation: Zhang J. Keeping a Healthy Figure Scientifically. Trends Nur Health Care Res. \\
2021;1(2):1-9. DOI: 10.53902/TNHCR.2021.01.000507
\end{tabular}


In this investigation, they were searching a giraffe which was injured by arrows smeared with some home-made poison for a whole day, like searching for toothpick dropped to the middle of 1000 -acre wheat field, to find that died poisoned giraffe, but the calories they cost for a whole day is still unchanged to a European worker who doesn't have such level of physical exercising. This searching is like only have experiments without theoretical proof or computation when doing scientific researches, the process needs no thinking, and men just hunt in this way for living every day, they do this for calories and the Hadza just eat and reproduce, nothing else interesting. And the life for them is just a game of hunting for living and bringing up kids, no evolutionary processes.

On another hand, the lives of European people, perhaps also like the majority of people in China, work in office and deal with many mental works daily, such works needs them to think and consumes much energy, but many of them don't have habits of exercising, and many of them get more or less obesity, i.e., they don't have a healthy figure like many sport enthusiasts have, like many athletes in Olympic Games have. A healthy figure comes from health and everyone likes to be healthy. If exercise does not help to weight losing or curing obesity, why those who have sports as hobby always have healthy figure and look better?

Actually, science already shows that having sports as habits, in sufficient and proper amount daily, makes people healthier. It stimulates various function of the human body so that they come to be used instead of being dead, the blood circulates better in body, the nerve and muscle systems get being trained; therefore, the whole body gets better nutrition due to exercising as well as exceeding compensation thereafter, which means those what were used in sports would become better in the rest thereafter, keeping habits of sports in long-term would thereby make a great difference to health. It has been already known that sports have such effects: ${ }^{1}$

1. Enhancing the cardiovascular circulation and cardio-pulmonary functions, lowering the risk of relevant diseases and many cancers. There was a case that a young man in England cured his lymphoma cancer by keeping exercising, who was encouraged by his girlfriend, despite this he also became a muscle man after two years.

2. Enhancing the endurance and strength of muscles.

3. Reducing fat and replacing fat with healthier tissues, lowering the risk of obesity.

4. Increase the density of bones, lowering the risk or reducing the symptoms of relevant diseases, it can prevent osteoporosis.

5. Keeping one to be younger, with a teenager-like face, more flexible and energetic skin. Many athletes showed this, they not only have better figure, also look more youthful.

6. Training the coordination of the neuron system as well as the abilities to response thereabout

7. Improving sleeping quality.

8. Enhancing the qualities of the body, better immunity.

No matter in what manner, living only for living is not different from animals, any creature knows to choose the what makes it live; however, man is different from animals, one selects not only for surviving but also what one likes, man works to live and man have what he likes which is different from animals, man doing things he likes and choose what he likes instead of others. This is probabilistic, anything happens not according to material, i.e., what gives one food or money, but more than that, also what makes one live better or what makes life more interesting and meaningful, purely according to what he likes. For this reason, what man likes is as important as living for a man, this is why we created and developed philosophy, science, sports and morality etc., teaching us as well as our descendants how to be a man, how to live better and more healthily as well as how to understand and control the nature etc., making us stronger and more intelligent. For what all people like should never conflict with each other, they coexist naturally, the harmony therebetween is how we exist and develop, everyone needs to treat others as how one wants to be treated, so to be good to others is also good to oneself, goodness is what man likes. Everyone wants to live better and more happily, doing things he likes, only have the love which is the only one he likes, not only to survive or to earn money.

The way how the Hadza people live is indeed in Eden, as written by Dr. Pontzer, but it is wrong that the life in Eden is an ideal life because man only knows to eat and reproduce there, not different from gorillas. Only living and reproducing, nothing interesting, no thinking, no learning, at least one should go to find and only have one who he likes as his love instead of others he doesn't like, and never to change once he found his love who he likes as well as likes him. The currency in Hadza, like in many worlds of animals, is still calories, like money in human society. Going bust means death, and one should save it therefore, it prohibits calorie burning and therefore limits the development of their brain, i.e., intelligence. The society of human has relatively higher civilization, people don't need to worry about calories so this makes the human race smarter, people can think more as there is abundant and extra calories to use and no worries to death therefrom, people could have higher intelligence by thinking and studying more, using their extra calories. And learning makes them more intelligent, it would also be easier for them to earn money thereby. The Hadza society is still a primary society that lacks stable production of foods, it is always in calories crisis, so they have to think less to save their calorie; therefore, though the Hadza people have more physical activities than European people who stay in office, they never think as much as European people, they don't have to think because they can survive in the their way of living and there is also not too much calories for that, as they need to cut their calorie consumption down therefor to 
save it. Wealth is important to develop higher intelligence for people live in society.

The daily routine for European population is mostly mental works, they need to think therein; however, many of them don't have habits of exercising, same to people in China. As a result, the European people burn the same calories each day as the physical activity burned each day for Hadza people, but European people don't exercise, and Hadza don't think, so it turns out that Hadza people who exercise everyday don't have higher energy expenditure than European people who don't exercise; therefore, it seems that physical exercise doesn't help to weight losing, but this is wrong. It is because the Hadza people cut down the calories for thinking that led to this result, not because the exercising itself doesn't burn calories, Hadza people increase physical exercise but cut down their brain works, so they still have same energy expenditure as European people; therefore, if letting European people exercise more while keeping same brain works, such as learning, altering bad habits with good ones, exercise would effectively increase burning of calories so that European could restrain their obesity, and keep to be healthier and thereby have better figures.

\section{Sport Makes One Healthier and Cleverer ${ }^{2}$}

Researches also show that sports make one cleverer. In some studies, as written in an essay by Dr. Schadwinkel, physical activity makes one more concentrated, calm and better receptiveness. Children can focus and fade out noisy stimulus better after sports, making them regulate themselves better so that they can learn better and more efficiently. Sports also make those top sportsman react to stress with less anxious and better mood. Sport itself not only trains people physically, but also mentally, their brains, neuron systems and willpower got trained therein. Cognitive controlling is a central mechanism of brain which is essentially to regulate behaviour and attention processes, it needs executive function when one doesn't want to continue with his automatic thinking and behaving modes. With abilities of attention and behaviour navigating, man can also alternate between many aspects of a same working, which is a part of the cognitive controlling. The supplementary motor Cortex has effect about behaviour sequence, primary motor Cortex is responsible for motion accomplishment. The small brain, is where to steer the magnitude and time-related sequence of motion. The forehead region of brain switches the processes of motion, and the frontal lobe is more strongly active in teamwork sports than in running and swimming. If one wants to ask which sport is better to do, it can just be chosen according to different abilities trained by the sports in detail. One meets the stress from time and opponent in tennis, this requires the brain works. In baseball, the baseball player can only get ready to hit when the ball flied towards, and this trains his impulse controlling ability. And the player must make a conscious decision based on observation, to interrupt the runner in confusion, to shoot the goal indirectly, or pass to a teammate? Better executive function shows better achievements in whichever of sports, learning and working.

With works that demand self-controlling, man can train their abilities of controlling themselves better. For example, when one wanted to keep clearing out the sport bag after the sport.

Firstly, changing habitual ways of behaviour needs attention and working memory to think how to clear out the sport bag after the sport. Then it needs one to inhibit something to withstand the temptation such as going to the fridge which deviate him from the goal before firstly unpacking the bag; thereafter, it requires the flexibility and self-control to unpack the bag. Same principles are applied to emotion or mind controlling which are comparable, man must take a deep breath first and then concentrate on the positive side instead of treating someone with prejudice. We work by our self-controlling and self-regulating abilities, and executive function are always needed therefor.

For human being, amino acids Tryptophan is a primary stage for neurotransmitter serotonin, they are mostly tied to the proteins and therefore cannot reach the blood-brain-cabinet; however, when one is doing sports, the fat beginnings to be burnt and more fatty acids are released thereby, which solutes the proteins of Tryptophan so that increases the free Tryptophan in the blood, about 75\% more, and they can hereafter be able to reach the blood-brain-cabinet to be converted into serotonin then, the increased serotonin is effective to memory-supporting, anxiety-removing and decision-lighting.

Training can not only stimulate muscle, but also neuronal networks. This is determined by growing factor BDNF, which increases the synaptic plasticity as well as the growth and longevity of neuronal cells. Exercising 20 to 40 minutes every day raise the concentration of BDNF more than $30 \%$, and it supports the regeneration of neuronal cells in hippocampus; therewith our memory for fact, personal experiences and special direction. It is worth keeping exercising all one's life.

The effect of exercising hold for a period of time but will also retreat if one never does it anymore. It is assumed that one who exercises regularly have more receptors for pouring out serotonin. The effect of exercising is absolutely chronic. This has been shown with old women, 18 months after a strength training of one to two times weekly for a year. With increased running duration BDNF concentration also rose up, and meanwhile it has an increasement after three months of daily continuous duration training itself. Furthermore, a test showed that duration training has long-lasting effects, those who had got a three months training can have an increase of BDNF in a following short training on a level that could only be reached with more months for those who hadn't got such trained 
before. It also seems that BDNF influence by physical training remains a kind of molecular memory.

It is necessary to keep exercising at least 30 to 45 minutes every day if one wanted to do something good to his body and mentality. Doctors recommend two to three times of duration training per week and to have light strength training often. A habit of exercising is basic to a healthy and happy life. And those who are aware of balanced nutrition and keep away from cigarette or over consuming of alcohol also get better brain and lower risks of diseases with high death rate.

The earlier to start to keep exercising, the more beneficial it is. Small children train their strength, flexibility and coordination by sports, and cognitive basic functions could get enhanced therein. As the sports helps children to concentrate, it is advisable to held sport classes in the morning. Better executive functions also correlate to higher performance in mathematics and languages; nevertheless, being able to learn more efficiently is not the only reason that decides success and happiness of life, sports also shape the attitude. Those who regularly train and learn are also motivating themselves again and again. Sports requires effort preparation and persisting power, one strengthens his willpower like training his muscle thereby.

No excuse to stop exercising, when the weather is bad etc., still keeping running or swimming, such attitude is meaningful to the learning and working. Effort is more important than gift, and gift is actually one's interests anyway, one get such a gift as long as he really likes, and one must keep working hard if one really likes.

There is good news that the brain can still establish new links after adult age, this is even forever feasible as long as one still lives; therefore, it is never too late to start keeping exercising. For example, those adults who exercise regularly have lower risk of dementia about $18 \%$, of Alzheimer the value is close to $26 \%$. Whoever is spiritually active and eat healthily, and refrain himself from cigarette and over consumption of alcohol has $60 \%$ lower risk of it. Sport is an all-rounded medicine for health, it prevents diseases with no side-effects as long as doing it properly and safely, and it is free (this paragraph is mostly translated from [2]).

\section{Man is Different from Animals}

Life in Hadza is so boring, nothing interesting to live in such a society, no learning, no reading, no thinking, nothing to improve oneself or his life. People just live like gorillas in such society, or sheep that are only eating and drinking, just making poisonous arrows to predate giraffes every day, and women work hard to gain foods from the wild to support their men's game of hunting day by day, like animal, nothing changes. The men, who hunt for the target giraffe, always spend large amount of time to search it like finding out a needle in the sea but without any theory, this wastes a lot of time because they are just trying all possibilities out, with no certainty of where the giraffe is, like using traditional computer to compute the probability distribution by computing each possible case one by one, that needs numerical computation costing large amount of time and power which is corresponding to large amount of calories and time of Hadza people, such computation or hunting requires too much energy and time and it is not generally feasible, not wise. If keeping this way in science research, one needs to try everything practically apparently for knowing; however, this would waste too much energy and time, like picking that needle in the sea, one could actually think more to guess and prove where this needle is, using his knowledge and the hint from how, when and where this needle was thrown into the sea, how was the sea at that time, at least he could restrain a relatively smaller range about where the needle is thereby, then one doesn't need to search every place in the sea to find it and perhaps one can compute out where the needle exactly is by his thinking. Similarly, there is also no necessity to try everything out for knowing for science study, one should think, guess, infer, prove and calculate etc. theoretically before experiments to figure out how our experiments to go to exactly find out the truth we want while never do anything wrong or bad, not only for avoiding useless efforts to save energy and time, also because that not everything can be done, e.g., rebelling ethic is evil in science. Scientists like Einstein all study with theoretical thinking to understand truths instead of trying everything out. It is wiser for the Hadza people to think where the giraffe could more possibly go before starting out to search for it.

It is certain that it is the calories intake larger than the calories needed that accumulates fat, and exercise can increase the energy expenditure effectively as long as one didn't cut down the energy expenditure spent on other beneficial activities; furthermore, it is better for one to alter all activities from non-beneficial to beneficial ones. Learning combined with proper exercising is a best way to increase energy expenditure, it does no harm and it would never be too much for oneself to think and study, while exercising cannot excess the healthy dose, both do no harm to the human and are what man likes, they make one be better, be what one likes to be. Exercising strengthens learning and thinking abilities, promotes calory burning thereabout. The lifestyle of Hadza people is fixed and they don't think as much as European. Their having same energy expenditure despite that European don't exercise and Hadza do much physical exercise doesn't indicate that physical exercising doesn't help to calories burning and weight losing. On the contrary, it just shows that thinking is remarkably effective to increasing energy expenditure and thereby restraining obesity, as long as one combines physical exercising and learning.

Both mental and physical activities burn calories, increasing physical activities while no cutting down to mental works, the calory burning can actually be increased effectively and thereby fat 
accumulation is restrained. The key to getting rid of obesity and keeping a healthy figure is to increase activities and eat healthily. One could increase thinking and learning while keeping exercising properly, and these are what man likes the best, because man can be more intelligent, talented, knowledgeable, skillful, healthier, stronger and wiser etc., one can be a better man thereby, making him as well as his life better; nevertheless, all these must be based on a good mood, happiness is what one want to get by all his activities and is also what provides him motivation and energy for all his activities, it is essential to support him to reach his goal and stick to learning and exercising, and thereafter can one be healthier so that get better figure.

Human is different from animals. Man is of idealism, man has love and abilities to choose what he likes, he chooses because he likes, not just what gives him foods or money, not determined by the material. Animals just want foods, like money in the human society, Hadza still use calories as currency, they are deterministic because the material determines their choice; whereas, what man chooses can't be predicted because he just chooses what he likes, and it is not necessarily money or food. Since man has love, man can actually change his habits, such as removing the time for video games into reading and exercising more. What man does is not totally determined by living, but more than living by what he likes, he wants to live better as well as to be better. A better life is not only material, but also spiritual. Man lives not like animals, foods or money buys everything of one, man lives for love. As ancient Chinese scholar Mencius said: "Both life and justice are what I like, and I choose justice when I can only choose one of them." Goodness is what man likes, what man likes is as important as one's life, they must be saved at the same time, man cannot live without goodness or what he likes.

Man can choose something more toilsome but more interesting to do because he likes, especially learning and exercising, and his energy burning could be increased to a healthier level thereby. The shortcut to lose obesity and have a healthy figure is to change one's habit, i.e., to keep learning and exercising daily, and don't waste time to do nothing, such as excess sleeping, rest is important but it should also not exceed the proper dose, have a long-distance running or swimming instead of playing boring video games or laying on the bed all-day along. Although this is toilsome, one is usually reluctant at the beginning, it is worth mentioning that love can change it: learning and exercising could make one more intelligent and healthier etc., and it makes the one who he likes like him more, because these not only enable one to get better life, but also make oneself more excellent, and excellence is attractive, health itself naturally makes better figure.

In fact, love is all motivation of a man, as Einstein said: love is the key of everything (a letter to his daughter). An ancient philoso- pher of China, Lao Zi said: Dào creates the "one", the "one" creates the "two", the "two" create the "three", and the "three" is what created everything. As Socrates said, the essence of a man is his free will; thereby, the "one" created by "Dào" should be the free will of the man. Then "one" creates two, the "two" should correspond to Tài Jí, ${ }^{4}$ because everyone has a unique counterpart who is the only one, he likes as well as he likes, who is complementary with him, like the Yīn Yáng in the Tài Jí diagram (Figure 1), each other is absolutely unreplaceable to each other, because they like each other. Also, there is love between the "two" intrinsically, and love is probabilistic, man choose and act totally according to his love, not deterministic. He loves because he likes, he did so because he likes. In the real probabilistic world, only love can be the reason why everything was created; therefore, when there is love, anything is possible, the "three" should be love and is what created everything.

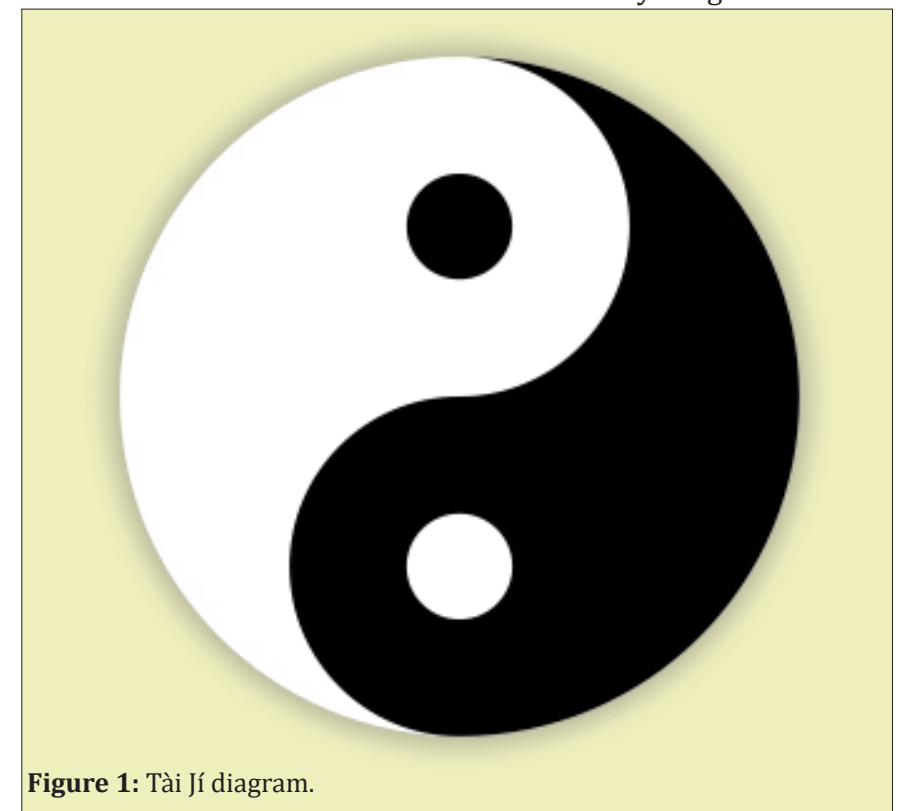

Perhaps the energy expenditure for an individual has its inertance, like the first law of Newton's three laws, keeping same energy expenditure is comfortable for an individual, because it is necessary to maintain the health of the whole life system of it to live, Life should be the inertia of living creatures, because animals are deterministic thereby, life is all of it, all what an animal do is only for living.

However, it is toilsome for an individual to increase the health of the whole life system, though man likes it, increasing health needs changing one's behavior and habits higher than only living, that is to accelerate such inertia life system to higher levels of lives, i.e., to live better, different from the natural direction which is only for living. Living is what man likes but what man likes is not only living, what man likes is more than living and is as important as life, it makes life better; thence, one needs his willpower to overcome the natural intention of only living that keeps same energy expenditure 
when he wanted to change his habits to lose obesity and get better figure, to become more intelligent, talented, skillful, knowledgeable, stronger, wiser and healthier etc., i.e., to be better and what he likes to be, to do things he likes and to live more healthily and happily, love is where this willpower comes from.

Those sedentary people think more to keep same level of energy burning as compared to their primary ancestors, like Hadza people, that is a compensation to satisfy the needs for keeping same energy expenditure of the body, thereby to keep fit in the most effortless way, though the health won't increase if only keeping in such a state. If the energy expenditure is not adequate, the excessive calories would make the body collapse, the individual will gain extra fat gradually, leading to obesity, this is painful, animal also doesn't want, this is just not what man likes, man intrinsically likes health; thence, it is man didn't love what he likes enough that leads to unhealth, including obesity. There is a word in "the inner Bible of the Yellow Emperor", "the Yáng Qì is like the sun on the heaven, one lose longevity and can't thrive if it was lost. The sun should be rightly on the heaven to shine everything (every creature on earth lives on it) in its orbit; therefore, Yáng Qì, like the sun to every creature on the earth, is the most essential element that keeps on healthy, also what protects his flesh." This Yáng Qì should be the similar thing as the mood in nutriology, or more than it, and love is what keep and earn it. It is possible that human's life can be extended infinitely therefor, with sufficient science and technology, as long as his will is there. ${ }^{5}$

Some may think one can save what he eats to prevent such excess accumulation of calories; however, life is movement, if there is no energy burning as well as energy intake, that is a dead machine, no life. Life should be more active therefore one must eat moderately and healthily, one can't only save diet to cure obesity.

Animals only do what makes them live and beneficial to their offspring, they would feel comfortable to keep same energy expenditures, this mechanism passively maintains their fitness, it is the natural selection of animals that only to live and to turn their energy into offspring, both are only living. Essentially, how Hadza people live is just the same, they hunt and gather foods from the wild to live, then reproduce, and the next generation still live the same manner as how their ancestors live, they don't think to live better, they don't think about whether there is better way to gain foods, they could at least think to directly find the target giraffe instead of trying every possibility out randomly; they don't think to do what they like to make their lives more interesting; so there are no increase of energy expenditure by thinking or doing something interesting, especially learning and exercising, their energy expenditure of this part was lost compared with European sedentary people, that's why they have same daily calories consumption as European sedentary people who don't do so much physical exercise every day.
They don't need working or studying, they can live but nothing would change as well, like sheep that are eating and drinking, they just hunt and gather food from the wild and then eat and reproduce, and teach their offspring to live in same way and reproduce, life is consequently extremely boring there. Hadza people transported the energy used for thinking by European into hunting, their total energy expenditure remains the same because they don't think like European people anymore, they have home-made poison for hunting and can get food from their women by gathering in the wild, enough for their surviving, no need to think. They only live for live, nothing interesting more. The result that the physical activity is weakly related to metabolism therefrom is just because that the mental works of the Hadza was cut down when increasing those physical activities, and that European and Hadza people have same energy expenditure despite that Hadza people have a lot of physical activities while the European not, is not because of that physical activity itself doesn't contribute to energy expenditure, but that people in Hadza give up what they like, they don't think and learn, don't think to do things they like and live better.

If one wants to increase his energy expenditure to lose obesity and get better figure, one should increase exercising while think and learn more. Though Hadza people exercise more, they subtly saved their energy by reducing their mental work, they only search the giraffe by searching everywhere without any certainty where the giraffe has gone. European people only work mentally without physical exercising and have the same energy expenditure, this inversely shows that mental works, i.e., learning and thinking, are effective to increase energy expenditure as physical exercising; thereby, one can lose obesity and get better figure. Moreover, mental activity has more potential therefor than physical exercising, man can increase the intensity and time of mental activities infinitely as long as he can, not like physical activities which can't exceed human's limitation and is healthy only when doing it in proper amount.

The lost energy expenditure from thinking is sufficient to account for the constancy of daily energy expenditure between people who exercise and don't exercise. Many participants who exercise cut down their energy expenditure for thinking, they think less because they sleep more, those time are originally for thinking and mental working, they could consume more energy to think when they are awake. Exercising modifies the quality of sleeping and people don't need to sleep more to get enough rest, if they are sleepy, it is possibly because the lack of some nutritional materials, such as Vitamin C in fruits, eating fruits is a good way to recover from the tiredness after exercising, in healthy amount.

Thinking is the most remarkable factor to make room for daily energy budget, spending more on physical activity while never cutting down learning and thinking, i.e., to scrutinize more time out for 
exercising and learning, the energy expenditure can be remarkably increased. Though exercising brings reduction of hormones after it, but it may also be followed by an over recovery therefrom, like exceeding compensation after sports.

The evolved strategies for keeping daily energy expenditure are justly based on laziness, increasing exercising while not reducing energy expenditure by mental works, replacing bad energy expenditure with good ones, the expenditure can effectively be increased. Combining physical exercising with same or more thinking and learning will remarkably increase energy expenditure and reduce obesity.

Obesity is a disease of both gluttony and sloth, moderate diet and proper exercise are essential to preventing obesity and keeping a healthy figure. Keep learning more while hitting the gym is effective to lose excess fat and to keep healthy; thereby, energy expenditure can be increased when people were more diligent to learn and exercise, like those physicists in $20^{\text {th }}$ century, they have formidable brains which are highly energy consuming, with proper exercising which improves abilities to learn and to think, like Alan Turing and Niels Bohr who also have qualities of athletes, their energy expenditure can be much highly improved, and they can keep their figure more easily while no need to cut down eating delicious and healthy foods.

However, only exercising is surly not enough for losing obesity and keeping a healthy figure, because the consumption from physical activities is too limited for the human being, one can't exercise too much otherwise it do harm to the person; therefore, people need to increase more beneficial brain works, i.e., thinking and learning while keeping exercising properly. As brain only consume energy from blood glucose, only glucose can supply energy therefor, and exercising consume energy from fat or protein only after the blood glucose is not enough for the energy supply in long-time low intensity training, learning more to consume more glucose previously can make fat be better consumed in physical exercising. ${ }^{3}$ Exercise does help to weight losing, but brain works such as learning is more energy consuming, though the fat still needs exercising to burn.

Changing habits, i.e., spending more time on exercising and learning instead of time to be lazy can increase energy expenditure effectively, and love can make one overcome the toilsome feeling when doing this. Hitting the gym is effective for losing obesity and keeping health, but it should also be combined with more learning and thinking. In a word, one should be more diligent. Despite weight losing, exercise also has more beneficial functions such as improved brain function, healthier aging etc., many studies showed it as mentioned in Sec.2. ${ }^{2}$

Moreover, if one love, he wanted to be more excellent, i.e., being more intelligent, knowledgeable, talented and healthier etc., one must be more diligent, paying toil and pain to learn and exercise harder; thereby, his energy expenditure must be leveled up and he needs to eat moderately and healthily to satisfy his nutrition demand, so it is not scientific to only concentrate on saving diet to control obesity.

If one wants to have better figure, one can't only focus on diet, only cutting down eating is not healthy, it is wrong. Life is movement, though it may still makes one slim, it keeps one away from being healthier, intelligent and stronger etc., keeps one away from what one likes which needs higher level of as well as more advanced activities; therefore, healthier and moderately eating combined with more beneficial activities, i.e., thinking, learning and exercising is the only way to lose obesity and keep healthy; thereby, one could be healthier, more intelligent and talent etc. while losing and preventing obesity, health makes better figure.

Daily energy expenditure is mobile, one could replace bad or lazy habits by other better and beneficial habit to increase energy expenditure, such as learning and exercising more instead of playing video games or sleeping all-day along, and always alter his habits with better ones.

Exercising is energy costing and it helps to weight losing against obesity, and it should be combined with more beneficial mental works, i.e., learning and thinking instead of wasting time, no cutting down to other beneficial energy costing activities and altering non-beneficial activities with beneficial ones. Learning and thinking actually count more for energy expenditure, they consume more amount of glucose in the blood; thereby, more glucose is consumed and fat accumulating could be prevented hereby. The brain and other neuronal tissues can only consume energy supplied from the glucose in blood, and the energy supply for exercising is firstly from the glucose in blood, too, only when persisting sports within moderate intensity for a long time which exhausted the energy supply from glucose, can the fat or protein start to be expended for energy supply; ${ }^{3}$ therefore, learning and thinking more can also make the exercising more effective to lose obesity and keep fit, mental and physical activities are complementary to each other for health and better figure.

Nothing in life is free? We can think, learn and exercise ourselves by loving, so that we can be more talented, intelligent, knowledgeable, wiser, healthier, stronger and skillful etc., be better, and this is free, because what man likes doesn't conflict with each other and love is free, we can be better and what we like to be while no other sacrifices; thereby, we can also get more powerful abilities to work and we can produce what we want ourselves.

Anything is possible, according to quantum field theory, real particles are actually the excitation states of quantum fields, which means the spontaneous symmetry breaking may create materials 
from null, as described by "the 'three' creates everything", love is the only possibility of this "three" that created everything; therefore, anything existent can definitely be produced by man's free will, i.e., love, and anything in imagination is possible. With sufficient science and technology man can created anything they want freely, love is free.

Love is the unlimited resource for man, because love happens as long as man thought and act it in practice. What man likes never conflict with each other because this is the nature, they coexist with harmony naturally, the nature itself never conflicts with itself. For this reason, man has love and can invest more love in one trait he likes while no cutting down to others he likes. If one likes, he just needs to work hard and think diligently to make it, anything is possible, he just needs to find the right ways to manage it.

Love is how man is different from animals. Rabbit is unable to choose what it likes itself, it just chooses foods and reproduce, so the resource for rabbits or animals are limited, more in one trait sacrifice others, their longevity was sacrificed when they reproduced more; however, the resource of man is unlimited because man has love, man can produce what he likes by diligent thinking, learning, exercising and working while no sacrifice of other traits he likes, learning and exercising make one more capable to work for what he likes.

Our energy expenditure is not puzzle, exercise does help to increase energy expenditure, except one should not cut down other beneficial activities which is energy costing, especially learning and thinking. One should combine them, learning and thinking more instead of wasting time such as excess sleeping and hunt in a hopeless way as Hadza people, when keeping exercising properly. Thinking and learning can levitate the energy expenditure effectively; thereby, one can lose obesity and be healthier while be more intelligent, talented, knowledgeable, skillful, cleverer, stronger, wiser, and excellent etc., i.e., be a better man, be what he likes; thereby, he can live better. One should also always alter all activities with more beneficial ones at the same time.

Since man has love, one does what man likes rather than simply surviving and reproducing, he wants to live better as well as be better himself. Same energy expenditure can therefore be used for more interesting things, like learning which makes man more intelligent and talented or exercising which makes man healthier and stronger, all is what man likes to be.

People think more and do what they like because they like. They learn and exercise more and they can be more intelligent, knowledgeable, skillful, talented, wiser, healthier and stronger etc. thereby. This makes their metabolism more suitable to support man's costly traits like more intelligent brain. Such energetically costly traits of human being are from the accumulation of generation by generation. They learn, exercise and work etc. to be more excellent as well as to live better, they keep doing so because they like, they do what man likes and it is love that motivated them constantly; furthermore, each of them only have the only one who he likes as well as likes him as his love and never change once they liked each other, such choice of purely likeness also determines better genes for their descendants.

As a result, their way of living would make a difference to their genes, they would remarkably keep evolving generation by generation, as they keep training their brains or bodies etc. by learning and exercising, doing things they like, and everyone only chooses the only one who he likes as well as likes him as the only love which can absolutely never be changed, their descendants would be more and more gifted for learning, exercising and whatever man likes to do, such traits accumulate generation by generation. As a result, their descendants will evolve towards what man likes continuously, so as to their lives, better and better.

The difference between the man and animal is that man has love, man do what he likes instead of simply living, one also wants his life and himself to be better, to be what he likes to be. The extra work done by our heads and bodies is to support our more intelligent brains and traits for doing what we like, man likes learning and exercising because man becomes more knowledgeable, talented, skilful, wiser, healthier, stronger etc. thereby, to be better and live better and more happily. Man is also different from animals that man gets what one wants by his own diligent working, not only consuming what is given in the nature or the society. Since man learns, thinks and works, man can freely produce better energy-rich foods that is difficult to obtain in the nature which allows us to fuel faster metabolism, as long as man is willing to make an effort for it.

We are not evolved to be fat, fat is not what man likes, people became fat is because the lack of love to overcome the laziness to change their habits to be healthy and excellent, especially the habits of learning and exercising instead of wasting time, such as excess sleeping, greediness or doing things without thinking. Thinking prevents the accumulation of obesity and exercising burns the excess fats off thereafter. If people want to lose obesity and be healthy, people need to love more, to put more time into beneficial and energy costing activities which they like, especially thinking, learning, exercising and working which are essential to the life of a man as well as living better. Man wants not only to live, but also to live better and be better himself. Our propensity to store fat is for times we loved more, i.e., we think, exercise, learn and work more and we got evolved thereby, but the lack of love abolishes them, they were not sufficiently utilized therefor accumulated as obesity. Such propensity, e.g., faster metabolism means that we must keep learning, ex- 
ercising and doing things we like harder and harder, keep thinking more and more diligently, keep evolving generation by generation, otherwise we will get ill or even die, such as obesity.

Sharing is the most ingenious and powerful weapon against starvation? No, it may be effective to an individual for a time but not effective in long term, everything of man can only be obtained from his own diligent working as well as the cooperation with the society, and it is working that produce everything needed by the people; therefore, learning and working is the only way to understand and develop the nature so that we can produce what we want ourselves, and everyone deserve the production by his own working cooperated with the society. Furthermore, man learn and work not only for living, but also for liking, man think, learn and exercise more to be more intelligent, talented, knowledgeable, skillful, stronger, wiser and healthier etc.; thereby, man can not only get more powerful abilities to work and to produce what they want so that to earn a better living, but also be better himself, to be what he likes to be.

Cooperation just helps the efficiency and abilities; however, learning and working is what is the most fundamental against starvation and for good living. Love is what makes man different from animals, man works to produce what they want themselves, thinking, learning and exercising can make men themselves more excellent, be better as well as mightier to work for what they want for living better. These are what man likes to do because one can be what he likes to be thereby. Animals only live and reproduce; life is all what they like but they don't think to live better, they don't have love, they don't have what they like.

However, animals still have some good qualities even they are just things and live only for living, the bees help to pollination; a dove has only one spouse all its life to whom it is persistent with, which is utilized by human to let them deliver letters for them, such delivery can reach a distance of thousands of miles. One must learn and work otherwise even animal is better than him, as written in "Bible of three words".

\section{Acknowledgement}

Thank to my supervisor who gave me the chance to study, thank my professors and teachers who taught me and gave me much help in learning. Thank all people over the world who worked diligently, it is them who paid toil and pain to create such a wonderful world where I can have such a good life, to think, learn and exercise freely, to thrive for living better. Thanks to my family, they are always supporting me.

\section{Funding}

None.

\section{Conflicts of Interest}

Author declares that there is no conflict of interest.

\section{References}

1. Yáng zé yì. A course to sport nutritionist. People's Sport Publication, Beijing; p. 196.

2. Training: port macht klug - Spektrum der Wissenschaft.

3. Zhāng Jūn, Zhāng Yùnkūn. Nutriology for Sports. Higher Education Press, Beijing; p. 5.

4. Chinese Gung Fu,The Philosophical Art of Self Defense. Bruce Lee Junfan. Beijing United Publishing Co,Ltd; pp. 38-41.

5. The Inner Bible of the Yellow Emperor. Chinese Bureau of Books. p. 27.

6. Herman Pontzer. Exercise Paradox. Scientific American. 2017. 